\title{
AN APPROACH TO ENHANCE PRODUCT UNIVERSALITY USING VAGUE NUMBERS DURING INITIAL DESIGN PHASE
}

\author{
Singh, Ravindra (1); \\ Tandon, Puneet (2) \\ 1: Delhi Technological University; \\ 2: PDPM Indian Institute of Information Technology, Design and Manufacturing, Jabalpur
}

\begin{abstract}
Universal design facilitates all user, a convenient interaction with the environment, product and services without the need for any adaptation and specialized designs. Recent studies have shown that designers and manufacturers are focusing only on a limited group of users during product development. Current design process or methodology cannot cater to all set of users i.e. Fully Abled People (FAP), Specially Abled People (SAP), and Differently Abled People (DAP) due to complexity in need interpretation. Identification and extraction of needs of diverse user set is a complex problem. Generally, information gathered from the users is linguistic in nature and comprises of uncertainties and ambiguities, which hamper conversion of users' requirements into product attributes to deliver universal solutions. The aim of this work is to eliminate these uncertainties and extract the actual needs of all users. This work proposes the integration of Universal Product Design model with generic design process to improve universal product design practice. Linguistic preferences of the users are captured and converted into vague numbers to identify the important product attributes and provides a systematic framework of need prioritization.
\end{abstract}

Keywords: universal design, Decision making, Design methods, Design practice, Early design phases

\author{
Contact: \\ Singh, Ravindra \\ Delhi Technological University \\ Design \\ India \\ ravindra@dtu.ac.in
}

Cite this article: Singh, R., Tandon, P. (2021) 'An Approach to Enhance Product Universality Using Vague Numbers During Initial Design Phase', in Proceedings of the International Conference on Engineering Design (ICED21),

Gothenburg, Sweden, 16-20 August 2021. DOI:10.1017/pds.2021.40 


\section{INTRODUCTION}

In recent years, the design community has evolved numerous design methodologies related to design for all. Universal Design (UD) is among them that deals with social justice and equality (Steinfeld Edward and Maisel Jordana, 2012). The focus of UD is to make the design accessible to all users rather than concentrating on users with specific disabilities. It may be further divided into two components

Integration of assistive technology into the product for making it usable by everyone, including those who have difficulty in efficient accessibility and use. (b) The product's design should be flexible enough for the users to use the product directly without involving assistive technology or design modifications (Vanderheiden, 1996). More individuals without disabilities would gradually realize that many product attributes are useful to them in several cases, too, rather than the target audience only for which they were designed (for example, ramps and grab rails). Universal design cannot work well unless all user segments' requirements and abilities are considered in the design process. To develop a truly universal product, the designer must consider all sets of users' essential requirements regardless of any disability (Demirbilek and Sener, 2003). Once the basic needs are identified, the developed product would cater to all users' sets, including with or without disabilities. However, identifying and prioritizing the basic needs is a complex problem that involves information scarcity and data ambiguity. Usually, the customer needs are vague and uncertain and cannot be extracted efficiently directly from the users (Chan et al., 2019; Tiwari et al., 2016). In practice, the correct user needs are acquired by interpreting the information gathered from data analysis. There is a need to develop a systematic framework, which will result in a truly universal product if incorporated into the generic design process. The proposed work develops a model based on User classification, Prioritization of needs, Design deliverables, called the Universal Product Design (UPD) model in this model, for generating a complete universal product with vague set theory. This work proposes to classify users into three groups for the UPD model based on their abilities and need. The first group consists of fully-abled people and hence labeled as Fully Abled People (FAP) in this paper. The second group consists of persons who have some special needs or temporary disability, i.e., the people who need assistive devices to operate normally. Such a group of people is called Specially Abled People (SAP). The third group consists of challenged people, i.e., people with permanent physical or mental disabilities. Such a group of people is called Differently Abled People (DAP) here. Further, users' needs are prioritized into five categories: one dimensional, attractive, indifferent, and reverse needs as per the KANO model (Xu et al., 2009a) and then converted accordingly to the product attributes. For example, must needs are essential to the users, and the product must provide sufficient fulfilment of these needs. To identify the product attributes, the designer needs to interpret the linguistic information gathered from the users into meaningful information. This work proposes to capture all linguistic preferences of users for product attributes and convert them into vague numbers to prioritize the users' needs (Qing Shen, 2010). The users' linguistic preferences are then aggregated using the modified Weighted Least Square Model (WLSM) method (Geng et al., 2010). Preference rules are formulated to classify these aggregated customers' preferences and be categorized into five tiers, i.e., Tier I to Tier V. If a product satisfies Tier I, II, and III needs, it would be classified as a truly universal design. The design deliverables are formulated based on the user classification and Prioritization of users' needs. Thus, the proposed approach can efficiently and effectively aid the product development process and produce true universal products.

\section{BACKGROUND STUDY}

This section presents universal design and coverage of different methods with the work done to develop the universal design and study the current universal design scenario. The magnificent outline of universal design was introduced in the "Universal Design Handbook" (Preiser, Wolfgang F. E., Smith, 2011). "Designing of a mainstream product, environment, and services that are usable by people with a diverse range of abilities within the roughest condition without the need for special adaptation design." The objective of universal design is not to design specialized and customized products for independent living of the people having special needs or differently-abled people, which is the aim of assistive technology (Biihler, 1996). It is also defined as developing a meaningful product, environment, and service that provides a better experience and efficient outcome for all users. The real purpose of universal design is to design products and environments for all sets of users to use and access the products and environment without any difficulty, thus, reducing the adaptation of 
personalized and specialized design. Today's design practice, products, and services may be too specialized and optimized for a particular segment of users and fail to adapt to other population sections (Huang et al., 2006). The primary focus of current design activities is majorly on fully-abled people (typical users). Unfortunately, designers in our society mistakenly assume that everyone under this definition of typical users or fully-abled people (FAP) (Connell et al., 1997). Some attempts have been made to widen the canvas of product design practices and refer to them as universal design. Still, such efforts address the needs of differently-abled and elderly people only. However, if the product is universally designed, it should not be labeled; nobody wants to use a labeled product for "elderly" or "physically challenged" people. A team of researchers at North Carolina State University has enumerated seven universal design principles (Connell et al., 1997). These seven principles are (i) equitable use, (ii) flexibility in use, (iii) simple and intuitive use, (iv) perceptible information, (v) tolerance for error, (vi) low physical effort, and (vii) size and space for approach and use. After reviewing the literature related to universal design shows that the topic is investigated from various perspectives. There are many products not accessible to a wide range of people. The majority of designers focus on developing the utility for someone with physical and skilled capabilities similar to their own unless specifically instructed to do so (Cooper, 1999). In practice, most designers focus on delivering the system's utility or functionality required for the task and social acceptability in the form of aesthetic characteristics for users who match their capabilities and taste. Such minimally effective solutions are increasingly unacceptable to the wider population (Clarkson et al., 2015). Enough time has passed since Ron Mace coined the term universal design in 1985, yet practitioners do not capture design-related understanding to develop universal products (Vanderheiden, Gregg, Tobias, 2000). Various frameworks include differently-abled and elderly into consideration to develop universal products. A user values-based evaluation model was proposed to assess the universal scale's product universality during the pre and post-design phase (Singh et al., 2020; Singh and Das, 2020; Singh and Tandon, 2016). Demirbilek and Demirkan had proposed a participatory framework to design and develop products (labeled as universal products) to promote and maintain the independent living of the elderly people (Demirbilek and Demirkan, 2004a). The stage is now set to include the demands of diverse sections of society in product design. The product should not cater just to the differently-abled people but also fully-abled people at the same time during the design phase. Developing a new inclusive design approach based on three principle stages in design (defining the problem, developing a solution, and evaluating the solution) was proposed by Clarkson and Keates (Keates, S. Clarkson, 2004). McAdams et al. explored the relationship between user activity, product form and function, and proposed framework and representation for universal design. The diagram based on the graphical representation called the action-function diagram helps identify functional morphological and parametric differences between simple and universal products that have similar use during the initial phase of design. This action-function diagram combines activity diagrams and functional models into a single graphical representation (McAdams and Kostovich, 2011). Specialized products aim to compensate for the loss of independence experienced by physically challenged people. As such products cater to special needs, they are called niche products. To improve their design and make them universal, EMFASIS framework (Extended Modularity, Functional Accessibility, and Social Integration Strategy) was proposed. EMFASIS framework eliminates the issues of stigmatization associated with assistive technology (Plos et al., 2012). Gonzalez and Morer (Gonzalez and Morer, 2016) proposed a theoretical framework for developing a digital guiding tool to help the industrial designer in the initial phase of the design process. This framework was based on three aspects of ergonomics, i.e., physical, cognitive, and emotional. It helps reduce an iterative process of correcting the product's measurable aspects and helps to gain a broader understanding of the user (Gonzalez and Morer, 2016). This study aimed to concentrate on the essential design requirements for adjusting the work environment for both elderly and young users from ergonomics. To enhance and promote the independent living of the elderly, a participatory model was proposed to develop fully safe, efficient, and functional products based on user involvement in the product design and development process (Demirbilek and Demirkan, 2004b; Reich et al., 1996). The designers need to consider the complete set of users to develop universal products. During the initial phase of design (discover and define), design professionals had to investigate the users' actual needs and convert them into product attributes. However, finalizing the product attributes based on the linguistic judgment is complicated due to an uncertain environment. Numerous approaches have been developed that support, validate or defend decision-making or concept evaluation based on non-numerical techniques to interpret 
linguistic judgments. These non-numerical approaches depend on the experience and qualitative analysis of an individual or a group of experts. Qualitative analysis is imprecise and has uncertain data, leading to poor accuracy and inefficiency (Geng et al., 2010). Some of the techniques for qualitative analysis include concept screening (Ulrich et al., 2020), decision matrix (Pugh, 1991), and Quality Function with a single Multiple Criteria Decision Making (MCDM) approach (Geng et al., 2010). Traditionally, universal design is thought to be aiming at helping differently-abled people or the elderly (Bady, 2012). This work's primary focus is to provide the necessary utility, functionality, social acceptability, and accessibility. Designers, on most occasions, develop products for a limited group of people, which is not the aim of the current universal design philosophy. This work also identifies the present practice of universal design that makes the product non-universal. There is no proper defined methodology that aims at providing design solutions for a wide range of people including differently abled and produce mainstream product instead of specialised products for elderly and disabled people. In general, the product is designed for a specific target. Many products are not accessible to a wide range of people. Therefore, a model's need was felt that can guide the designer during the early design phase. The universal design would not even succeed if some users found its appearance unappealing, inappropriate, or awkward to use (Aslaksen et al., 1997). Many products are designed for Differently Abled People and Specially Abled People (DAP and SAP). However, they do not cater to a larger segment of users; because of a perception of inappropriateness. At times, there is awkwardness in their use also, which restricts their merger with mainstream products. Another matter of concern is related to decision-making during the initial design phase. After user study, the gathered data is converted into meaningful information to identify the product attributes during the initial design phase. However, the users' data is vague and uncertain, due to which the selected product attributes do not satisfy a broad range of people. It was observed that many products limit access to a wide range of users. Thus, it was felt that if a model based on user classification and need Prioritization is developed, it would not only minimize uncertainty during the initial design phase (before concept generation) but also lead to true universal design. The proposed UPD model approach is developed to resolve the identified issues.

\section{RESEARCH APPROACH AND PROCEDURE}

To better understand the needs and aspirations of people, this work categorizes the entire population into three groups based on their needs and abilities. It is also possible to classify the users into more sets and subsets but based on pre-experimentation and user study. It is proposed to incorporate the UPD model shown in Figure 1 in the generic design process to develop true universal products. The primary purpose of selecting the generic design process is to encourage the designers towards universal design to develop products for the masses. UPD model consists of three stages, as mentioned below: Stage 1: Construction of a hierarchy of users based on their needs (guided by Maslow's need hierarchy) (Maslow, 1943). Stage 2: (i) Prioritization of needs derived from Kano model (ii) Conversion of the linguistic preferences of the users into vague sets by using vague set theory to capture an accurate perception of customer needs. Stage 3: Formulation of design deliverables.

\section{UNIVERSAL PRODUCT DESIGN (UPD) MODEL}

The Universal Product Design (UPD) model proposed to develop true universal products is based on User classification, Prioritization of needs, and Design. User classification leads to the categorization of users into three groups. The needs of users are further classified into five categories based on users' priorities. Using the Kano model concept, the needs are prioritized: needs, one-dimensional needs, attractive needs, indifferent needs, and reverse needs (Xu et al., 2009). Moreover, the vague set theory is included in the UPD model to capture the users' linguistic preferences regarding product attributes. The users' preferences are represented as vague numbers (Chou, 2012; Qing Shen, 2010). With the Weighted Least Square Model (WLSM) help, all linguistic preferences are then aggregated. After that, preference rules are formulated to classify customers' aggregated preferences and categorize the preferences into Tier I-must be need, Tier II-functional need, Tier III- attractive need, Tier IVindifferent, or Tier V- reverse need. If any product satisfies all the Tier I, II, and III needs, then it would be a truly universal design. In the end, design deliverables are formulated. Thus, the proposed approach can efficiently overcome the drawbacks of current product development processes and 
produce true universal products. UPD model (Figure 1) helps the designer uncover the users' needs for the development of a universal product.
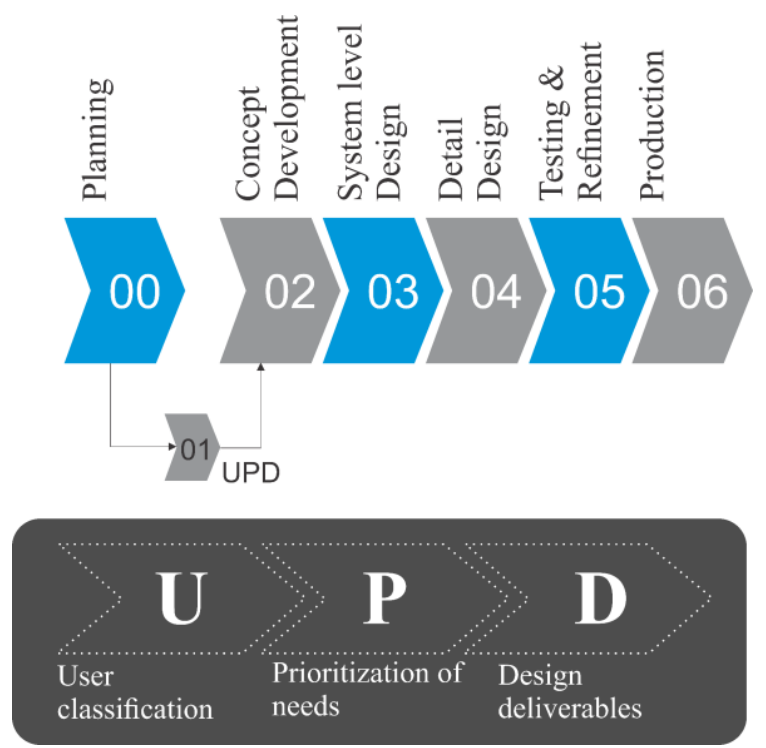

Figure 1. Integration of UPD model into generic product design process (Ulrich et al., 2020)

\subsection{User classification}

Users are broadly categorized into three groups based on Benktzon's user pyramid and inclusive design cube (Benktzon, 1993; Clarkson et al., 2015). The users may have been classified into a larger number of groups to showcase the diversity of research, but it was observed that three groups are just and sufficient for the work. The people's classification is as follows: The first group consists of people with permanent physical and mental disability; such group of people is called Differently Abled People (DAP). The second group consists of people who have special needs or any temporary disability, i.e., the people who need some assistive products to operate normally. Such a group of people is called Specially Abled People (SAP). The third group consists of fully-abled people and hence labeled as Fully Abled People (FAP) here. User classification and its involvement in the design process are essential for developing universal products. To achieve a truly universal product, designers need to classify the users hierarchically to identify the actual need of the users based on some priority. An example of such a hierarchical model could be the hierarchy of needs (Maslow, 1943). The hierarchy of needs principle specifies that for a holistic solution, a designer must fulfill the lower-level or basic needs before aiming at higher-level needs

\subsection{Prioritization of needs}

The user needs can be prioritized by first recognizing how vital the identified need is to the user and capturing the user's correct perception about the need through vague set theory, respectively.

\subsubsection{Importance of needs}

incorporate some feature into the product to cater to other remaining groups, i.e., SAP and DAP as Similarly, the products that were initially meant for SAP, designers at times, add a few features that may suit the requirements of DAP to improve the scope of their application. In other words, in the conventional mode, designers attempt to adapt a product initially designed for either FAP or SAP for different sets of people to increase their universality. However, current design approaches are neither sufficient to cater to all users nor produce universal products. While designing a product for elderly and differently-abled people, designers merely try to include a few product features that fulfill the people belonging to special categories to meet their aspirations out of the product. The outcome of the above design practice is a non-universal product that satisfies only one (or limited) ICED user group at a time. The universality cannot be achieved until all users get involved in the early phase of the design process, and their needs and aspirations are considered effectively into the solution. In this sub-model, core benefits/attributes and users' needs are identified using the KANO model concept. Kano analysis is a quality measuring tool used to prioritize user requirements based on their impact on user satisfaction. 
Kano's model addresses five types of user's needs. 1. Basic needs (Tier I) or must be: this is the basic need of a product/service, and users are highly dissatisfied in its absence. However, the fulfillment of this need does not increase satisfaction since users take it for granted. 2. Functional / performance (Tier II) or one-dimensional needs: this need is positively and linearly related to user's satisfaction, i.e., users' satisfaction increases with the fulfillment of this need, and vice versa. 3. Excitement needs (Tier III) or attractive needs: Users are satisfied if this need is addressed but are not dissatisfied if it is absent. 4. Indifferent need (Tier IV): the fulfillment of this need does not bring satisfaction or dissatisfaction. 5. Reverse need (Tier V): Its fulfillment causes dissatisfaction. Taking an example of a cellular (mobile) phone, two-way communication is an essential need of the cellular phone. One-dimensional needs make a higher contribution to user satisfaction, e.g., simple operation (man-machine interface) and high processing speed for mobile phones will increase user satisfaction. Attractive needs are meant to attract potential users, e.g., camera quality, high data storage, etc., for a cellular phone. Indifferent needs remain neutral and do not make any contribution to the user satisfaction e.g. a stylus-equipped mobile phone as an alternative to a traditional paper notebook, is an advance feature of the smartphone that is preferred by very few people. Reverse needs cause dissatisfaction, it also assists designer to eliminate such need during ideation (Seder and Alhazza, 2014).

\subsubsection{Capturing true perception through vague numbers}

Capturing users' true perceptions during the initial design phase is an essential task to be performed by a designer. However, it is tough to capture a true perception of the users. Usually, information gathered from the users is in linguistic form. It has a lot of ambiguous data, which is insufficient to deliver a design solution to all users' satisfaction. Vague numbers or vague set theory are used to reduce the vagueness from the gathered data. The vague number is expressed and calculated based on the methodology proposed by Geng et al. (Geng et al., 2010). They used vague numbers in the concept evaluation process to express the decision-makers linguistic judgment on the criterion for design alternatives. In this work, vague numbers are used to calculate the customers' true perceptions for generated product attributes.

The vague set theory consists of truth membership and false membership function. For example, $x=\left(x_{1}, x_{2} \ldots x_{n}\right)$ e the universal set. Vague set $\mathrm{V}$ on $\mathrm{x}$ is defined mathematically as

$V=\left\{\left(x,\left[t_{v}(x), 1-f_{v}(x)\right]\right) \mid x \in V\right\}$, where $t_{v}(x)$ is truth membership function and $f_{v}(x)$ is false membership function and, $0 \leq t_{v}(x)+f_{v}(x) \leq 1$. Hesitancy degree, denoted by $\pi_{v}(x)$ Determines whether $\mathrm{x}$ belongs to vague set $\mathrm{V}$ or not. $\pi_{v}(x)$ is mathematically computed by $1-\left(t_{v}(x)+f_{v}(x)\right)$. The values of truth membership function, false membership function, and hesitancy degree meet the following two conditions: $t_{v}(x)+f_{v}(x)+\pi_{v}(x)=1$

$0 \leq t_{v}(x), f_{v}(x), \pi_{v}(x) \leq 1$

A group of customers $\left\{c_{k} \mid 1 \leq k \leq C\right\}$ give their judgments on each generated product attributes based on a Likert scale, i.e., very satisfied, satisfied, neutral, dissatisfied, and dissatisfied. The customer is denoted by $\mathrm{C}$. These judgments are then converted into vague numbers to capture customers' true perceptions. The importance weight of each customer is represented by $w_{k}$, where $\sum_{k=1}^{C} w_{k}=1,0 \leq$ $w_{k} \leq 1$.The vague number for each customer's linguistic judgment is calculated as per Geng et al. (Geng et al., 2010). For each judgment, the vague number is expressed in mathematical form as $\left[t^{\prime}(x)-\alpha \pi(x), t^{\prime}(x)+\beta \pi(x)\right]$, where $\alpha+\beta=1$. $\alpha$ and $\beta$ denote higher and lower hesitancy degree respectively. Value of $t^{\prime}(x), \alpha, \beta$ is predetermined and shown in Table 1.

$p_{i}^{k}(k=1, \ldots, C)$ represents the preference of the customers on each product attribute, $A_{j}(j=$ $1, \ldots, n) . p_{i}^{k}$ is expressed in the form of a vague number $\left[p_{i l}^{k}, p_{i u}^{k}\right]$, where $0 \leq p_{i l}^{k} \leq p_{i u}^{k} \leq 1$. After obtaining all customers' preferences for each product attribute, the customers' aggregated preferences are calculated by finding the deviation measure between each customer judgment and final aggregated judgment. A modified Weighted Least Square Model (WLSM) method (Geng et al., 2010) calculates aggregated preferences. The deviation degree between $p_{i}^{k}$ and final aggregated judgement, $p_{i}$ is computed by

$d^{2}\left(p_{i}^{k}, p_{i}\right)=\frac{1}{2}\left[\left(p_{i l}^{k}-p_{i l}\right)^{2}+\left(p_{i u}^{k}-p_{i u}\right)^{2}\right]$ 
Table 1. Linguistic response and the corresponding vauge numbers (Geng et al., 2010)

\begin{tabular}{|c|c|c|}
\hline Linguistic variable & Vague number & Values of $\alpha, \beta$ \\
\hline Very Dissatisfied (VD) & {$[0.1-\alpha \times \pi, 0.1+\beta \times \pi]$} & $\alpha=0, \beta=1$ \\
\hline Dissatisfied (D) & {$[0.3-\alpha \times \pi, 0.3+\beta \times \pi]$} & $\alpha=\beta=0.5$ \\
\hline Neutral (N) & {$[0.5-\alpha \times \pi, 0.5+\beta \times \pi]$} & $\alpha=\beta=0.5$ \\
\hline Satisfied (S) & {$[0.7-\alpha \times \pi, 0.7+\beta \times \pi]$} & $\alpha=\beta=0.5$ \\
\hline Very Satisfied (VS) & {$[0.9-\alpha \times \pi, 0.9+\beta \times \pi]$} & $\alpha=1, \beta=0$ \\
\hline
\end{tabular}

The aggregated preferences are calculated by minimizing the total deviation degree $D_{i}$, considering the importance weight of customers, which is as follows

Min

$$
D_{i}=\sum_{k=1}^{C} d^{2}\left(p_{i}^{k}, p_{i}\right)=\frac{1}{2} \sum_{k=1}^{C} w_{k}\left[\left(p_{i l}^{k}-p_{i l}\right)^{2}+\left(p_{i u}^{k}-p_{i u}\right)^{2}\right]
$$

s.t $0 \leq p_{i l}^{k} \leq p_{i u}^{k} \leq 1, k=1, \ldots, C$

Finally, an aggregated vague number of attributes is investigated based on the following evaluation rules (Table 2).

Table 2. Evaluation rule

\begin{tabular}{|c|c|c|}
\hline S. No. & Type of need & Vague Number \\
\hline 1. & Must be & $0.8 \leq p_{i l}^{k} \leq p_{i u}^{k} \leq 1$ \\
\hline 2. & One dimensional & $0.6 \leq p_{i l}^{k} \leq p_{i u}^{k} \leq 0.8$ \\
\hline 3. & Attractive & $0.4 \leq p_{i l}^{k} \leq p_{i u}^{k} \leq 0.6$ \\
\hline 4. & indifferent & $0.2 \leq p_{i l}^{k} \leq p_{i u}^{k} \leq 0.4$ \\
\hline 5. & Reverse & $0 \leq p_{i l}^{k} \leq p_{i u}^{k} \leq 0.2$ \\
\hline
\end{tabular}

\subsection{Design deliverable: an attributes}

In this section, the design document is formulated based on the above two sub-modules. A design deliverable is a written document for a project; it focuses on the desired results of design. Once the needs and attributes are well defined in writing, designers create concepts with the help of design deliverables. The design deliverables' main aim is to provide clear information to the designers and the manufacturer for developing a tangible product. Design deliverables offer a complete insight into the users' needs in the form of customers' voices to evolve the product attributes. This sub-module also acts as a self-communicator for the designers. If a designer is trying to create a concept, selfcommunication is necessary because it is hard to focus on all aspects of the problem and the customer requirements. This design deliverables sub-module allows designers to shift their attention from one aspect to another without any effort. The design deliverables are also used to answer various hypothetical questions posed by the client and manufacturer.

\section{DESIGN TEST CASE: SMART MOBILE PHONE}

In this section, designing a smart mobile phone for all users is taken as an example to demonstrate the application of the generic universal product design process. Of late, mobile phones have become essential for individuals, whether they are differently-abled, or with special needs, or typical users. In 
this exercise, the focus is on the early design phase, i.e., understanding the users' needs (customer requirement) and selecting product attributes that satisfy all sets of users. As shown in Table 3Seventeen product attributes are identified for this case study with the help of product catalogues, ecommerce websites (Amazon, eBay, Flipkart, etc.), focus groups, and brainstorming sessions. A total of forty-five users, fifteen from Fully Abled People, Specially Abled People, and Differently Abled People user sets, are involved in the exercise. All forty-five participants were asked to rate the product attributes based on their needs on the Likert scale (very dissatisfied to very satisfied). The response of all forty-five participants is recorded for converting the linguistic data into a numeric form to eliminate the uncertainty from the gathered data.

\section{Table 3. List of product attributes}

\begin{tabular}{|l|}
\hline Attributes \\
\hline A1- Voice quality; A2- Message (A/V); A3- Voice to Text; A4- Multifunctional; A5- Entertainment \\
A6- A/V recording; A7- Large Display; A8- QWERTY Keypad; A9- Simple operation; A10- Dual \\
SIM; A11- Performance; A12- Compatibility with other devices; A13- Memory; A14- Operational \\
Speed; A15- Ergonomics; A16- Lightweight; A17 Aesthetics
\end{tabular}

To obtain the consensus judgments of all forty-five users, each user group's weight is first determined. The analytical hierarchy process (AHP) is used for assigning weights to user groups because it provides a comprehensive framework to solve problems associated with decision making. For the design test case, the AHP study involved 30 participants, including 10 participants from DAP; (considering visually impaired, deaf, physically challenged), 10 participants from SAP (Elderly, children, pregnant women, etc.), and 10 participants from FAP, which includes college students, working professional, etc.). After a pairwise comparison among user groups (DAP, SAP, and FAP), the user's priorities were found. With the AHP approach, user group priority was $0.54, .253$, and .207 for DAP, SAP, and FAP, respectively. Linguistic responses of the user sets (FAP, SAP, and DAP) on each attribute were converted into vague numbers using vague set theory. All responses to each attribute were then aggregated by using Eq. 4 . Finally, all attributes were identified based on priorities, as shown in Table 4

Table 4. Identified attributes based on priority

\begin{tabular}{|c|c|c|c|}
\hline Attributes & Vauge number & $\begin{array}{c}\text { Aggregated } \\
\text { Vague number }\end{array}$ & Category \\
\hline A1 & $0.629-0.817$ & 0.72 & One dimensional \\
\hline A2 & $0.611-0.792$ & 0.70 & One dimensional \\
\hline A3 & $0.578-0.765$ & 0.67 & Attractive \\
\hline A4 & $0.442-0.617$ & 0.52 & Attractive \\
\hline A5 & $0.535-0.749$ & 0.64 & Attractive \\
\hline A6 & $0.522-0.729$ & 0.62 & Attractive \\
\hline A7 & $0.601-0.783$ & 0.69 & Attractive \\
\hline A8 & $0.518-0.687$ & 0.60 & Attractive \\
\hline A9 & $0.440-0.585$ & 0.51 & Attractive \\
\hline A10 & $0.523-0.697$ & 0.61 & One dimensional \\
\hline A11 & $0.610-0.813$ & 0.71 & indifferent \\
\hline A12 & $0.380-0.560$ & 0.47 & Attractive \\
\hline A13 & $0.504-0.684$ & 0.59 & \\
\hline
\end{tabular}




\begin{tabular}{|c|c|c|c|}
\hline A14 & $0.723-0.877$ & 0.80 & Must be \\
\hline A15 & $0.622-0.800$ & 0.71 & One dimensional \\
\hline A16 & $0.567-0.767$ & 0.66 & Attractive \\
\hline A17 & $0.517-0.710$ & 0.61 & Attractive \\
\hline
\end{tabular}

\section{CONCLUSION}

The current universal design practice, which focuses on limited user segments, requires an approach to cater to all users' sets, including those with and without disabilities (FAP, SAP, and DAP). This paper investigates the decision-making approach during the initial design phase by integrating the UPD model into the generic design process. Identifying users' needs of all sets of users for a universal product plays a vital role during the initial design phase. Still, it is difficult to convert the customers' voice into product requirements due to uncertainty and ambiguity present in the linguistic form. To handle ambiguity and uncertainty, the UPD model is inserted into the generic product design process to understand the needs of the users and identify the product attributes. It is normally considered that a hundred percent $(100 \%)$ universality may not always be achieved in a single product, feature, or element. The most frequent trade-off that universally designed products encounter is their affordability. The UPD model further helps the decision-maker by providing an interface for identifying the user study's actual needs during the pre-design phase. The proposed approach is based on user classification along with need identification and prioritization. The vague set theory is used to classify the users' needs in five tiers (Tier I, II, III, IV, or V), which helps deliver universal products. A mobile phone design exercise had been conducted to check the effectiveness. UPD model aims to provide ease and appropriate user insights to the designers to guide them to evolve universal solutions to product design problems. It is difficult for a designer to convert customer voice into user requirements to generate the desired product attributes due to associated uncertainties and ambiguities in the linguistic form. To handle ambiguity and uncertainty, a vague set theory is used. Post users need prioritization, which helps designers or decisionmakers eliminate associated uncertainties with user preferences and convert qualitative information into useful quantitative data. UPD model is augmented into the generic product design process to understand users' needs and identify the product attributes to develop the universal products.

\section{REFERENCES}

Aslaksen, F., Bergh, S., Bringa, O.R. and Heggem, E.K. (1997), Universal Design: Planning and Design for All, available at: http://home.online.no/ bringa/universal.htm.

Bady, S. (2012), "Professional Builder".

Benktzon, M. (1993), "Designing for our future selves: the Swedish experience", Applied Ergonomics, Vol. 24 No. 1, pp. 19-27.

Biihler, C. (1996), "Approach to the analysis of user requirements in assistive technology", International Journal of Industrial Ergonomics, Vol. 17, pp. 187-192.

Chan, C.W., Green, L. V., Lekwijit, S., Lu, L. and Escobar, G. (2019), "Assessing the impact of service level when customer needs are uncertain: An empirical investigation of hospital step-down units", Management Science, Vol. 65 No. 2, pp. 751-775.

Chou, J.R. (2012), “A linguistic evaluation approach for universal design”, Information Sciences, Vol. 190, pp. 76-94.

Clarkson, P.J., Waller, S. and Cardoso, C. (2015), “Approaches to estimating user exclusion”, Applied Ergonomics, Elsevier Ltd and The Ergonomics Society, Vol. 46, pp. 304-310.

Connell, B.R., Jones, M., Mace, R., Mueller, J., Mullick, A., Ostroff, E., Sanford, J., et al. (1997), “The Center for Universal Design - Universal Design Principles", available at: http://www.ncsu.edu/ncsu/design/cud/about_ud/udprinciplestext.htm (accessed 25 April 2015).

Cooper, A. (1999), The Inmates Are Running the Asylum, The Inmates Are Running the Asylum, available at:https://doi.org/10.1007/978-3-322-99786-9_1.

Demirbilek, O. and Demirkan, H. (2004a), "Universal product design involving elderly users: a participatory design model.", Applied Ergonomics, Vol. 35 No. 4, pp. 361-370.

Demirbilek, O. and Demirkan, H. (2004b), "Universal product design involving elderly users: A participatory design model", Applied Ergonomics. 
Demirbilek, O. and Sener, B. (2003), "Product design, semantics and emotional response”, Ergonomics, Vol. 46 No. 13-14, pp. 1346-1360.

Geng, X., Chu, X. and Zhang, Z. (2010), "Expert Systems with Applications A new integrated design concept evaluation approach based on vague sets", Expert Systems With Applications, Elsevier Ltd, Vol. 37 No. 9 , pp. 6629-6638.

Gonzalez, I. and Morer, P. (2016), "Ergonomics for the inclusion of older workers in the knowledge workforce and a guidance tool for designers", Applied Ergonomics, Vol. 53, pp. 131-142.

Huang, H.-Z., Bo, R. and Chen, W. (2006), “An integrated computational intelligence approach to product concept generation and evaluation”, Mechanism and Machine Theory, Vol. 41 No. 5, pp. 567-583.

Keates, S. Clarkson, P.J. (2004), Countering Design Exclusion: An Introduction to Inclusive Design, Springer ed.

Maslow, A.H. (1943), “A theory of human motivation.”, Psychological Review.

McAdams, D.A. and Kostovich, V. (2011), “A Framework and Representation for Universal Product Design”, International Journal of Design, Vol. 5 No. 1, pp. 29-42.

Plos, O., Buisine, S., Aoussat, A., Mantelet, F. and Dumas, C. (2012), “A Universalist strategy for the design of Assistive Technology”, International Journal of Industrial Ergonomics, Elsevier Ltd, Vol. 42 No. 6, pp. 533-541.

Preiser, Wolfgang F. E. , Smith, K.H. (Ed.). (2011), Universal Design Handbook Second Edition, Second Edi., McGraw Hill.

Qing Shen, Y.J. (2010), "Fuzzy Sets, Rough Sets and Vague Sets”, 3rd International Conference on Advanced Computer Theory and Engineering (ICACTE), No. 2, pp. 461-465.

Reich, Y., Konda, S.L., Monarch, I.A., Levy, S.N. and Subrahmanian, E. (1996), "Varieties and issues of participation and design”, Design Studies, Elsevier, Vol. 17 No. 2, pp. 165-180.

Seder, A.M.F. and Alhazza, M.H.F. (2014), "Review on the Theory Of Attractive Quality Kano Model", Journal of Advanced Science and Engineering Research, Vol. 4 No. 2, pp. 88-102.

Singh, R. and Das, P.P. (2020), "An Approach to Develop Accessible and Affordable Products", Procedia CIRP, Elsevier B.V., Vol. 91, pp. 489-493.

Singh, R., Seniaray, S. and Saxena, P. (2020), "A framework for the improvement of frugal design practices", Designs, Vol. 4 No. 3, pp. 1-12.

Singh, R. and Tandon, P. (2016), "User values based evaluation model to assess product universality", International Journal of Industrial Ergonomics, Elsevier B.V, Vol. 55, pp. 46-59.

Steinfeld Edward and Maisel Jordana. (2012), Universal Design: Creating Inclusive Environments, John Wiley \& Sons, available at:https://doi.org/10.1007/s13398-014-0173-7.2.

Tiwari, V., Jain, P. and Tandon, P. (2016), “Advanced Engineering Informatics Product design concept evaluation using rough sets and VIKOR method", Advanced Engineering Informatics, Elsevier Ltd, Vol. 30 No. 1, pp. 16-25.

Ulrich, K.T., Eppinger, S.D. and Yang, M.C. (2020), Product Design and Development Seventh Edition.

Vanderheiden, Gregg, Tobias, J. (2000), "Universal design of consumer products: Current industry practice and perceptions", Proceedings of the IEA 2000/HFES 2000 congress.

Vanderheiden, G.C. (1996), "Universal Design... What it is and what it isn't".

Xu, Q., Jiao, R.J., Yang, X., Helander, M., Khalid, H.M. and Opperud, A. (2009a), “An analytical Kano model for customer need analysis", Design Studies, Elsevier Ltd, Vol. 30 No. 1, pp. 87-110.

Xu, Q., Jiao, R.J., Yang, X., Helander, M., Khalid, H.M. and Opperud, A. (2009b), "An analytical Kano model for customer need analysis”, Design Studies, Elsevier Ltd, Vol. 30 No. 1, pp. 87-110. 